\title{
Dynamic contrast enhanced-magnetic resonance imaging for the early evaluation of the response to docetaxel in rats with epithelial ovarian cancer
}

\author{
SU-JUAN YUAN ${ }^{1}$, TIAN-KUI QIAO ${ }^{1}$, JIN-WEI QIANG ${ }^{2}$ and SONG-QI CAI ${ }^{3}$ \\ Departments of ${ }^{1}$ Oncology and ${ }^{2}$ Radiology, Jinshan Hospital, Medical Center of Fudan University, Shanghai 201508; \\ ${ }^{3}$ Department of Radiology, Zhongshan Hospital, Medical Center of Fudan University, Shanghai 200032, P.R. China
}

Received September 8, 2018; Accepted March 15, 2019

DOI: 10.3892/or.2019.7124

\begin{abstract}
Dynamic contrast enhanced-magnetic resonance imaging (DCE-MRI) contributes to the early detection and prediction of responses to chemotherapy in cancer. The aim of the present study was to investigate the feasibility of quantitative DCE-MRI parameters for noninvasively predicting the early response to DTX in epithelial ovarian cancer (EOC). In the present study, using 7,12-dimethylbenz (A) anthracene, orthotopic EOC was induced in Sprague Dawley rats. Rats with EOC were treated with docetaxel (DTX) on day 0. DCE-MRI was applied on days $0,3,7,14$ and 21 . On day 21 , the treated tumor types were categorized into sensitive and insensitive groups according to their change in size. Quantitative DCE-MRI parameters were used to assess the early response to therapy. The experiment was performed again, the treatment group was divided into sensitive and insensitive groups according to their initially obtained cut-off values, and histopathological analyses were performed. Comparing the sensitive group with the insensitive group, there were significant differences in the percentage change in the volume transfer constant $\left(\mathrm{K}^{\text {trans }}\right)$, rate constant $\left(\mathrm{k}_{\mathrm{ep}}\right)$ and initial area under the curve (IAUC) from day 3 and tumor size from day 14. During the early stages of treatment (on day 3 ), the percentage change of $\mathrm{K}^{\text {trans }}$ combined with $\mathrm{k}_{\mathrm{ep}}$ produced an AUC of 1 , and a sensitivity and specificity of 100 and $100 \%$, respectively, using a cut-off value of a $17.59 \%$ reduction in $\mathrm{K}^{\text {trans }}$ and $\mathrm{k}_{\mathrm{ep}}$. From day 7 , there were significant differences in the quantitative index percentage change in angiogenesis in the sensitive group compared with the insensitive group. The percentage change in $\mathrm{K}^{\mathrm{trans}}, \mathrm{k}_{\mathrm{ep}}$ and
\end{abstract}

Correspondence to: Professor Jin-Wei Qiang, Department of Radiology, Jinshan Hospital, Medical Center of Fudan University, 1508 Long Hang Road, Jinshan, Shanghai 201508, P.R. China E-mail: dr.jinweiqiang@163.com

Key words: angiogenesis, vascular endothelial growth factor, epithelial ovarian cancer, dynamic contrast enhanced-magnetic resonance imaging, sensitivity, specificity
IAUC were positively correlated with the percentage of change in tumor size and angiogenesis, and negatively correlated with the percentage of change in necrosis. The results of the present study indicated that quantitative DCE-MRI parameters were superior to imaging tumor size for the early detection and prediction of the response to DTX chemotherapy in EOC.

\section{Introduction}

Ovarian cancer is the leading cause of mortality from gynecological cancer globally (1). Taxanes-platinum combination have become the first-line chemotherapeutic regimen used against advanced epithelial ovarian cancer (EOC), which accounts for $85-90 \%$ of all ovarian malignancies (2). Taxanes, docetaxel (DTX) included, are widely recognized as a viable treatment method, and have been indicated to inhibit tumor angiogenesis and cell proliferation, induce tumor cell apoptosis and suppress tumor growth (3-5). Despite the encouraging survival benefits, not every patient with EOC responds to therapy in a satisfactory manner due to resistance or insensitivity $(6,7)$. Detecting treatment responses early will benefit these non-responders. At present, cancer antigen 125 detection and the Response Evaluation Criterion in Solid Tumors (RECIST) are widely used to clinically assess treatment responses $(8,9)$. However, size changes due to therapy tend to appear later compared with changes in the underlying tumor functions, including vascularization and vascular permeability $(10,11)$. This emphasizes the need to develop reliable methods for predicting early responses to therapy in order to replace unsuccessful drugs with potentially more effective therapeutic methods.

As a non-invasive imaging method, dynamic contrast enhanced-magnetic resonance imaging (DCE-MRI) contributes to the evaluation of tumor vasculature function and has increasingly been applied in animal experiments and clinical trials to predict early tumor responses to therapy (12-16).

However, it has not yet been determined whether quantitative DCE-MRI is able to predict the early response to DTX in EOC or whether there are associations between DCE-MRI parameters and the tumor size or histopathological changes. Therefore, the present study aimed to investigate whether quantitative DCE-MRI parameters may be used to determine an early treatment response to DTX in induced rat EOC by 
assessing the association of these parameters with tumor size, vascular endothelial growth factor (VEGF) levels and microvessel density (MVD) of the tumor.

\section{Materials and methods}

Tumor model and treatment. All animal experimental procedures were ethically approved by the Institutional Review Board of Jinshan Hospital of Fudan University (Shanghai, China) and were performed according to the Guide for the Care and Use of Laboratory Animals of the National Science and Technology Committee of China. A total of 160 female Sprague-Dawley rats (8 weeks old, 150-200 g; Shanghai Laboratory Animal Research Center, Shanghai, China) underwent surgery to establish orthotopic rat EOC. They were fed sterile water and food and housed under controlled temperature (at $25 \pm 1^{\circ} \mathrm{C}$ ) and relative humidity (40-60\%) conditions, with a 12-12 h light-dark cycle. The surgical procedures and protocol for the induction of EOC were performed as previously described (17).

MRI scanning. After anesthetization with pentobarbital sodium (40 mg/kg, i.p.) via the caudal vein, rats underwent MRI scanning using a $3.0 \mathrm{~T}$ scanner (Verio; Siemens Healthineers, Erlangen, Germany) with a rat coil. The following sequences were obtained: Axial spin echo (SE) T1 weighted image $(\mathrm{WI})=[$ repetition time $(\mathrm{TR}) /$ echo time $(\mathrm{TE})]=7.29 / 2.28 \mathrm{msec}$; axial, sagittal and coronal turbo SE T2WI with fat saturation $=\mathrm{TR} / \mathrm{TE}=2,500 / 93 \mathrm{msec}$; and turbo $\mathrm{SE}$ T2WI $=\mathrm{TR} / \mathrm{TE}=8,000 / 98 \mathrm{msec}$.

For DCE-MRI, pre-contrasted fast low angle shot-two dimensional T1WI with fat saturation $(\mathrm{TR} / \mathrm{TE}=7.92 / 2.28 \mathrm{msec})$ was performed at two different flip angles $\left(3^{\circ}\right.$ and $\left.15^{\circ}\right)$ for $\mathrm{T} 1$ mapping. Subsequent to the acquisition of four baseline scans, a dose of $0.2 \mathrm{mmol} / \mathrm{kg}$ gadopentetate dimeglumine (Magnevist; Bayer AG, Leverkusen, Germany) was administered to the rats via the caudal vein at a rate of $0.3 \mathrm{ml} / \mathrm{sec}$, followed by a bolus injection of $0.4 \mathrm{ml}$ saline at the same rate. A total of 30 phases of images were sequentially acquired with intervals of $6 \mathrm{sec}$. The scan parameters for the DCE-MRI were as follows: Slice thickness, $1 \mathrm{~mm}$; no gap; spatial in-plane resolution, 224x370; $\mathrm{TR} / \mathrm{TE}=5.27 / 2.14 \mathrm{msec}$; flip angle, $15^{\circ}$; and field of view, $80 \times 62.5 \mathrm{~mm}$. The total acquisition time was $4 \mathrm{~min}$. DCE-MRI was performed in an axial plane covering the entire tumor volume.

DCE-MRI processing and analysis. Using tissue four-dimensional software (Siemens Healthineers) and two-compartment modeling (18), DCE-MRI analysis was performed by two radiologists, each with 10 years of experience in pelvic MRI, who were blinded to the original information By avoiding hemorrhage, necrosis and major vascular structures, regions of interest of $20-50 \mathrm{~mm}^{2}$ in size were manually drawn on the slice to determine the longest diameter of the ovarian tumor types. Quantitative parameters, including the volume transfer constant $\left(\mathrm{K}^{\text {trans }}\right)$, rate constant $\left(\mathrm{k}_{\mathrm{ep}}\right)$, extravascular extracellular space volume ratio $\left(\mathrm{v}_{\mathrm{e}}\right)$ and initial area under the curve (IAUC), were automatically generated. MRI morphological features, including the tumor size, shape, boundary and mass configuration, were also assessed on T2WI.
Histopathological and immunohistochemical (IHC) analysis. Subsequent to validation (Fig. 1B) following the completion of the MRI scans at every time point, one rat ovary was removed and fixed for hematoxylin and eosin staining to evaluate the histopathology and tumor necrosis. IHC staining of VEGF and cluster of differentiation 31 was performed in order to investigate the expression of VEGF and the MVD, as previously described (17). A total of three high power fields (magnification, $\mathrm{x} 200$ ) were randomly selected and the tumor necrosis rate was semi-quantitatively analyzed using Image-Pro Plus 6.0 imaging software (Media Cybernetics, Inc., Rockville, MD, USA). Tumor necrosis rate $=$ necrotic area/field area $\mathrm{x} 100 \%$.

Experimental design. The study consisted of training and validation phases (Fig. 1). During the training phase (Fig. 1A), 24 rats were randomly assigned to treatment $(n=16)$ and control $(n=8)$ groups. The rats in the treatment group received $12 \mathrm{mg} / \mathrm{kg}$ DTX on day 0, as previously described (19). All rats underwent conventional MRI and DCE-MRI scanning on days $0,3,7,14$ and 21 post-treatment. On day 21 following DTX therapy, rats with EOCs were divided into a sensitive group (a tumor with decreased or unchanged tumor size) and an insensitive group (tumor with increased tumor size) according to RECIST guidelines and a previous study $(20,21)$. DCE-MRI parameters and tumor sizes at different time points (days 3, 7, 14 and 21) between the three groups were compared. Youden's index, which indicated the cut-off value that was used as the predictive factor for determining an early response to therapy (the optimal time point for the percentage change in the DCE-MRI parameters), was obtained using logistic regression analysis and receiver operating characteristic (ROC) curve analysis. In the validation phase (Fig. 1B), the experiment was repeated, and a further 101 rats received the same DTX therapy and MRI scanning as those in the training phase. The treatment group was divided into sensitive and insensitive groups at the optimal time point according to the obtained Youden's index. A number of rats in every group at different time points and in the control group on day 0 were sacrificed by cervical dislocation for histopathological and IHC analyses. In the two phases, only rats validated to have EOC (confirmed by autopsy and histopathology) were included in the study. Non-epithelial ovarian tumor types were excluded from the study. The numbers of rats sacrificed with EOC in different groups and at different time points are listed in Table I.

Statistical analysis. Data were analyzed using SPSS 22.0 (IBM Corp., Armonk, NY, USA) and values are presented as the mean \pm standard deviation. One-way analysis of variance was used for data analysis between multiple groups, and comparisons between every two groups were performed using Fisher's least significant difference test. Spearman's correlation analysis was used to analyze the correlation between the percentage changes in DCE-MRI parameters and the percentage changes in tumor size, VEGF, MVD and tumor necrosis as follows: A correlation coefficient between 0.75 and 1.00 was considered highly relevant, a coefficient between 0.50 and 0.74 was considered moderately relevant, a coefficient between 0.25 and 0.49 was considered weakly relevant and a coefficient $\leq 0.249$ was not considered relevant as previously described (22). $\mathrm{P}<0.05$ was considered to indicate a statistically significant difference. 
Table I. Numbers of rats with epithelial ovarian cancer in the different groups and at different time points following treatment.

\begin{tabular}{|c|c|c|c|c|c|}
\hline Group & Day 0 & Day 3 & Day 7 & Day 14 & Day 21 \\
\hline Treatment group & 56 & & & & \\
\hline Sensitive group & $35(0)$ & $35(8)$ & $27(8)$ & $19(10)$ & $9(9)$ \\
\hline Insensitive group & $21(0)$ & $21(4)$ & $17(6)$ & $11(5)$ & $6(6)$ \\
\hline Control group & $45(10)$ & $35(8)$ & $27(9)$ & $18(10)$ & $8(8)$ \\
\hline
\end{tabular}

The number of rats sacrificed for histopathology are indicated in parentheses.

Table II. The change rate in the tumor size at different time points $(\%)$.

\begin{tabular}{lccrr}
\hline Group & Day 3 & Day 7 & Day 14 & Day 21 \\
\hline Sensitive & $-2.17 \pm 5.35$ & $-4.82 \pm 5.14^{\mathrm{a}}$ & $-10.90 \pm 3.05^{\mathrm{a}, \mathrm{b}}$ & $-30.46 \pm 3.05^{\mathrm{a}, \mathrm{b}}$ \\
Insensitive & $4.09 \pm 6.69$ & $5.53 \pm 4.77$ & $5.44 \pm 2.95$ & $20.58 \pm 4.24$ \\
Control & $8.53 \pm 4.33$ & $14.77 \pm 5.63$ & $22.41 \pm 8.26$ & $37.49 \pm 9.64$ \\
\hline
\end{tabular}

Tumor size $=$ longest diameter. Data are represented as means \pm standard deviation. ${ }^{\mathrm{a}} \mathrm{P}<0.05$ vs. control; ${ }^{\mathrm{b}} \mathrm{P}<0.05$ vs. insensitive.
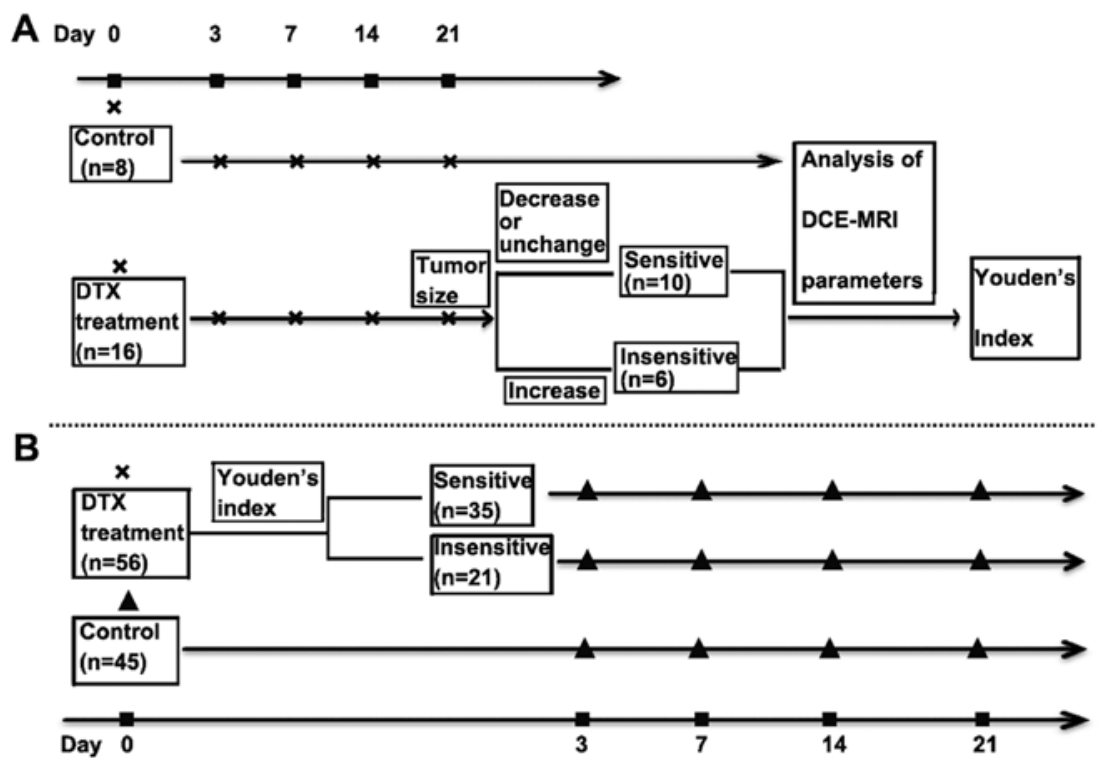

Figure 1. Flow chart of the study design showing grouping, treatment and imaging time points. (A) DCE-MRI was performed for all rats on day 0 after which they were randomly assigned to treatment and control groups. The rats in the treatment group received $12 \mathrm{mg} / \mathrm{kg}$ DTX on day 0 . Post-treatment (day 0) and 3, 7, 14 and 21 days after DTX therapy, all rats underwent MRI scanning under anesthesia. Twenty-one days after DTX therapy, tumors with decreased or unchanged longest diameters were categorized into a sensitive group, with increased ones into an insensitive group. Youden's index was obtained by means of retrospective logistic regression analysis of the DCE-MRI parameters at different time points (Tumor size indicates the longest diameter; Youden's index indicates the cut-off value that was the predictive factor for assessing early therapy response at optimal time point in $\Delta \%$ of parameters; ' $x$ ' indicates DCE-MRI; ' $\bullet$ ' indicates the time of DCE-MRI). (B) The rats received the same DCE-MRI and DTX as those in A. According to the above cut-off value at optimal time point, the treatment rats were categorized into sensitive or insensitive groups. Several rats in the control group on day 0 and in every group at a different time point were sacrificed and the tumors were excised for histology ( ' $\mathbf{\Lambda}$ ' indicates DCE-MRI and histology). \% Change in DCE parameter $=\left(\right.$ DCE parameter $_{\text {subsequent to treatment }}-$ DCE parameter $\left._{\text {day } 0}\right) /$ DCE parameter $_{\text {day } 0} \mathrm{x} 100 \%$.

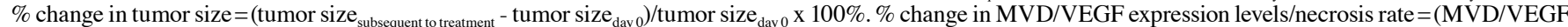

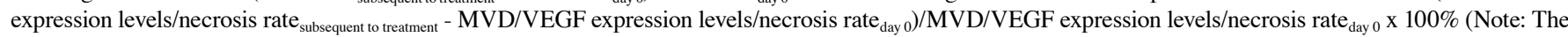
tumor size indicated the longest diameter of the tumor. $\mathrm{MVD}_{\mathrm{day} 0}, \mathrm{VEGF}_{\mathrm{day} 0}$ and necrosis $\mathrm{day}_{0}$ were the mean expression levels of the corresponding biomarkers in the control group on day 0). DCE-MRI, dynamic contrast enhanced magnetic resonance imaging; DTX, docetaxel.

\section{Results}

Tumor size changes in rat EOC subsequent to DTX therapy. As presented in Fig. 2, on days 0,3 and 7, the difference in the mean tumor size of EOC among the three groups was not significant $(\mathrm{P}>0.05)$. From day 14 onwards following DTX administration, the tumor size of the sensitive group was significantly decreased compared with the insensitive and control groups $(\mathrm{P}<0.05)$. As presented in Table II, the percentage change in tumor size was not significantly different between 


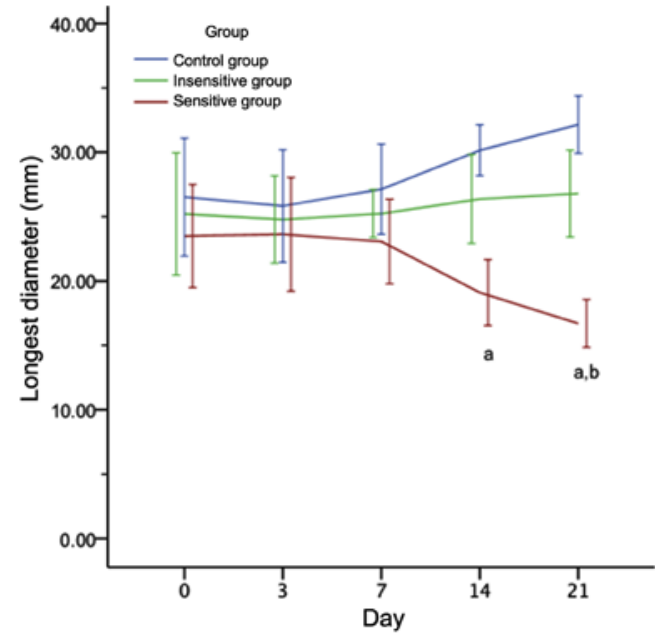

Figure 2. Effect of DTX on tumor size in rat EOC. The tumor size values were obtained from conventional MRI. The tumor size values are presented as the mean \pm standard deviation. From day 14 after DTX administration, the tumor size of the sensitive group was significantly decreased compared to its insensitive and control counterparts. Tumor size indicated the longest diameter. ${ }^{a} \mathrm{P}<0.05$ vs. control; ${ }^{\mathrm{b}} \mathrm{P}<0.05$ vs. insensitive. DTX, docetaxel; EOC, epithelial ovarian cancer; MRI, magnetic resonance imaging.

the three groups on day $3(\mathrm{P}>0.05)$. On day 7 , there remained no significant difference in the sensitive group compared with the insensitive group $(\mathrm{P}>0.05)$, but there was a significant decrease in the sensitive group compared with the control group $(\mathrm{P}=0.028)$. On days 14 and 21, significant differences were observed between the sensitive and insensitive or control groups $(\mathrm{P}<0.05)$. However, there was no significant difference between the insensitive and control groups $(\mathrm{P}>0.05)$.

DCE-MRI parameter changes in rat EOC subsequent to DTX therapy. On days 0,3 and 7, there were no significant differences in the DCE-MRI parameters $\left(\mathrm{K}^{\text {trans }}, \mathrm{k}_{\mathrm{ep}}\right.$ and IAUC) of the EOC compared between the three groups $(\mathrm{P}>0.05)$. On days 14 and 21, there were significant differences obtained in all pairwise comparisons $(\mathrm{P}<0.05)$, except for $\mathrm{K}^{\text {trans }}, \mathrm{k}_{\mathrm{ep}}$ and IAUC in the insensitive group compared with the control group (Fig. 3). The percentage changes of the DCE-MRI parameters in the different groups at different time points are summarized in Table III. On days 3, 7, 14 and 21, there were significant differences in the pairwise comparisons between the percentage change of the DCE-MRI parameters $\left(\mathrm{K}^{\text {trans }}, \mathrm{k}_{\mathrm{ep}}\right.$ and IAUC), except for the comparison of the insensitive group with the control group. The $\mathrm{v}_{\mathrm{e}}$ and percentage change in the $\mathrm{v}_{\mathrm{e}}$ lacked significant differences between the three groups at all time points $(\mathrm{P}>0.05)$. Figs. 4 and 5 present representative MRI images of the sensitive and insensitive groups respectively.

ROC evaluation based on DCE-MRI parameters. On days 0,3 and 7, the $\mathrm{K}^{\text {trans }}, \mathrm{k}_{\mathrm{ep}}, \mathrm{v}_{\mathrm{e}}$ and IAUC did not achieve a statistically significant difference in the sensitive group compared with the
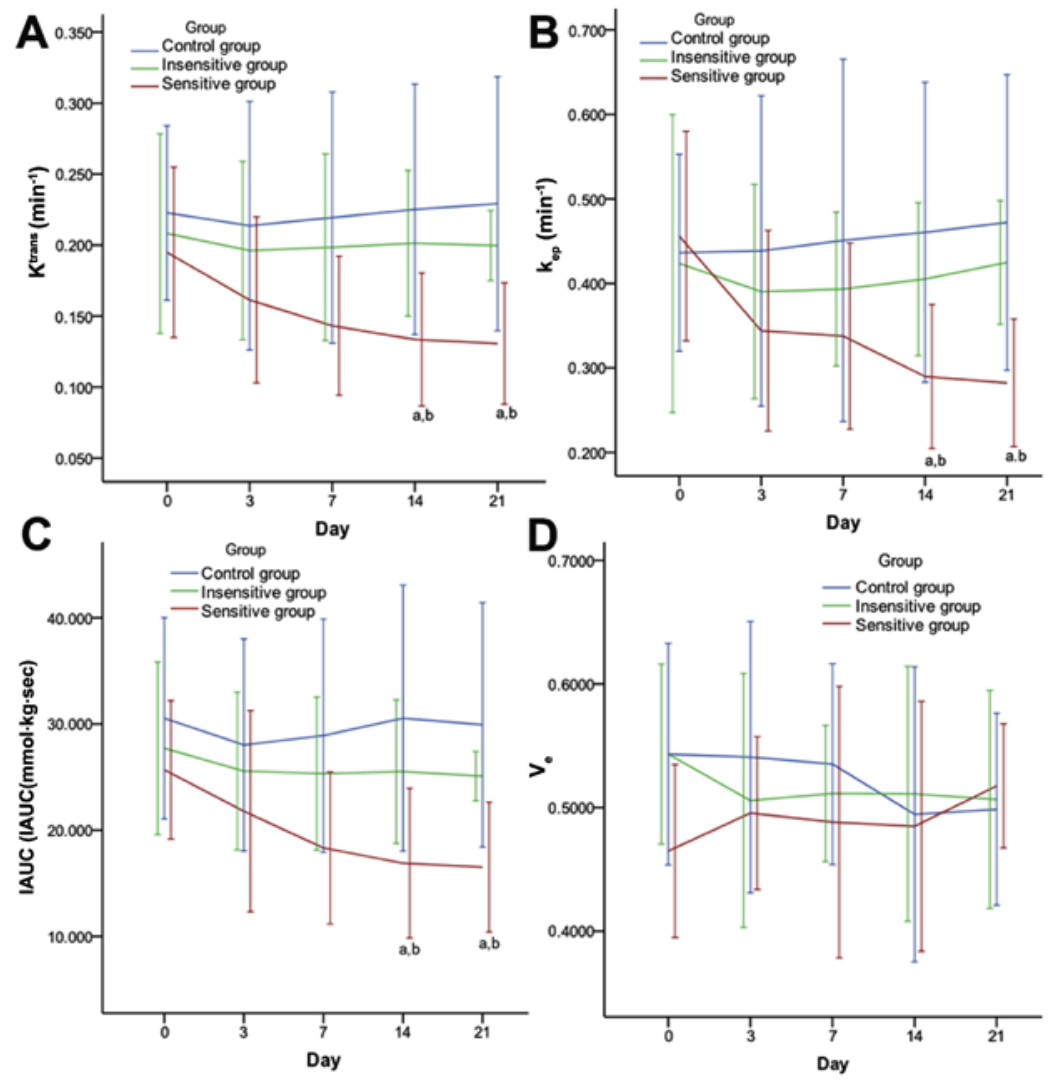

Figure 3. Effect of DTX on DCE-MRI parameters in rat EOC. Quantitative parameters [(A) $\mathrm{K}^{\text {trans }}$, (B) $k_{\mathrm{ep}}$, (C) IAUC and (D) $\left.\mathrm{v}_{\mathrm{e}}\right]$ were achieved with Tissue 4D software and two-compartment (Tofts) modeling (Verio; Siemens Healthineers, Erlangen, Germany). From day 14 after DTX administration, DCE-MRI parameters, $K^{\text {trans }}(A), k_{e p}$ (B), IAUC (C) included, of the sensitive group were significantly decreased compared to its insensitive and control counterparts. Data are represented as means \pm standard deviation. ${ }^{a} \mathrm{P}<0.05$ vs. control; ${ }^{\mathrm{b}} \mathrm{P}<0.05$ vs. insensitive. DTX, docataxel; DCE-MRI, dynamic contrast enhanced magnetic resonance imaging. $\mathrm{K}^{\text {trans }}$, volume transfer constant; $\mathrm{k}_{\mathrm{ep}}$, rate constant; $\mathrm{v}_{\mathrm{e}}$, extravascular extracellular space volume ratio; IAUC, initial area under the curve. 
Table III. Change in dynamic contrast enhanced-magnetic resonance imaging parameters at different time points (\%).

\begin{tabular}{|c|c|c|c|c|c|}
\hline Time & Group & $\begin{array}{c}\% \text { Change in } \\
\text { volume transfer } \\
\text { constant }\end{array}$ & $\begin{array}{l}\% \text { Change } \\
\text { in rate } \\
\text { constant }\end{array}$ & $\begin{array}{c}\% \text { Change in extravascular } \\
\text { extracellular space } \\
\text { volume ratio }\end{array}$ & $\begin{array}{c}\% \text { Change in initial } \\
\text { area under } \\
\text { the curve }\end{array}$ \\
\hline \multirow[t]{3}{*}{ Day 3} & Sensitive & $-20.55 \pm 2.40^{\mathrm{a}, \mathrm{b}}$ & $-22.44 \pm 5.65^{\mathrm{a}, \mathrm{b}}$ & $6.38 \pm 9.39$ & $-17.83 \pm 4.28^{\mathrm{a}, \mathrm{b}}$ \\
\hline & Insensitive & $-3.28 \pm 4.28$ & $-0.51 \pm 5.50$ & $-0.99 \pm 4.92$ & $-1.56 \pm 2.55$ \\
\hline & Control & $6.75 \pm 1.70$ & $9.06 \pm 7.42$ & $-1.42 \pm 8.98$ & $5.08 \pm 3.61$ \\
\hline \multirow[t]{3}{*}{ Day 7} & Sensitive & $-29.19 \pm 1.92^{\mathrm{a}, \mathrm{b}}$ & $-23.39 \pm 4.04^{\mathrm{a}, \mathrm{b}}$ & $-9.19 \pm 10.12$ & $-29.11 \pm 1.93^{\mathrm{a}, \mathrm{b}}$ \\
\hline & Insensitive & $-1.56 \pm 4.53$ & $-5.57 \pm 3.57$ & $-0.67 \pm 14.39$ & $-2.93 \pm 5.64$ \\
\hline & Control & $9.87 \pm 1.55$ & $9.51 \pm 17.05$ & $-3.28 \pm 6.71$ & $7.40 \pm 3.31$ \\
\hline \multirow[t]{3}{*}{ Day 14} & Sensitive & $-34.04 \pm 3.05^{\mathrm{a}, \mathrm{b}}$ & $-32.88 \pm 5.36^{\mathrm{a}, \mathrm{b}}$ & $3.69 \pm 8.03$ & $-33.32 \pm 5.71^{\mathrm{a}, \mathrm{b}}$ \\
\hline & Insensitive & $1.80 \pm 5.46$ & $-2.73 \pm 5.81$ & $6.69 \pm 8.19$ & $-1.65 \pm 4.35$ \\
\hline & Control & $13.05 \pm 1.19$ & $15.89 \pm 7.15$ & $-5.85 \pm 10.35$ & $12.47 \pm 4.68$ \\
\hline \multirow[t]{3}{*}{ Day 21} & Sensitive & $-33.80 \pm 4.44^{\mathrm{a}, \mathrm{b}}$ & $-32.85 \pm 7.27^{\mathrm{a}, \mathrm{b}}$ & $-8.52 \pm 7.14$ & $-33.17 \pm 6.47^{a, b}$ \\
\hline & Insensitive & $3.48 \pm 6.44$ & $4.48 \pm 9.93$ & $3.35 \pm 8.09$ & $0.34 \pm 8.70$ \\
\hline & Control & $15.14 \pm 1.26$ & $18.92 \pm 8.36$ & $-5.29 \pm 8.63$ & $11.32 \pm 4.62$ \\
\hline
\end{tabular}

${ }^{\mathrm{a}} \mathrm{P}<0.05$ vs. control; ${ }^{\mathrm{b}} \mathrm{P}<0.05$ vs. insensitive.

A
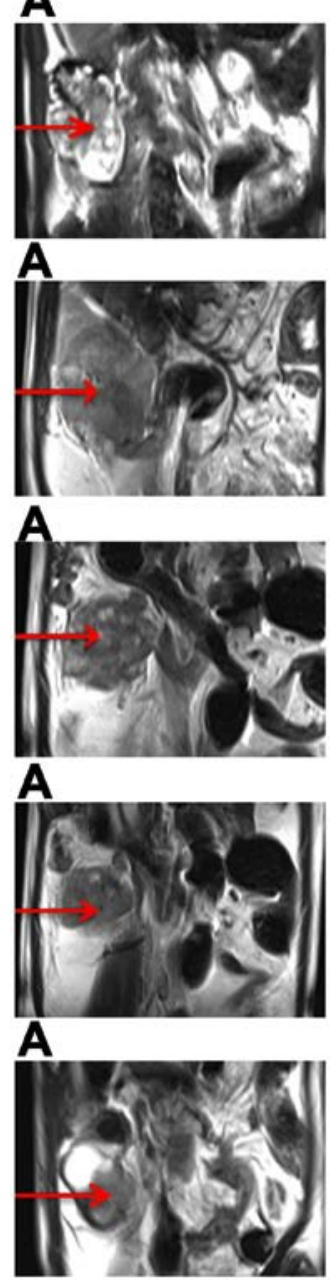

B
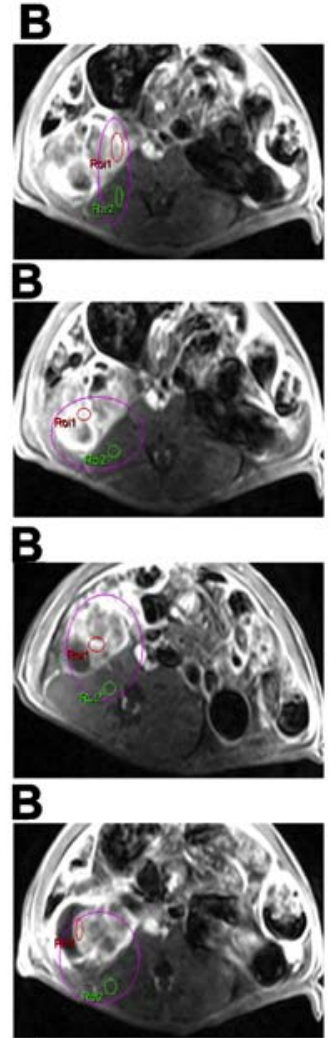

B

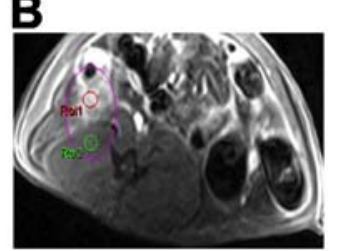

C
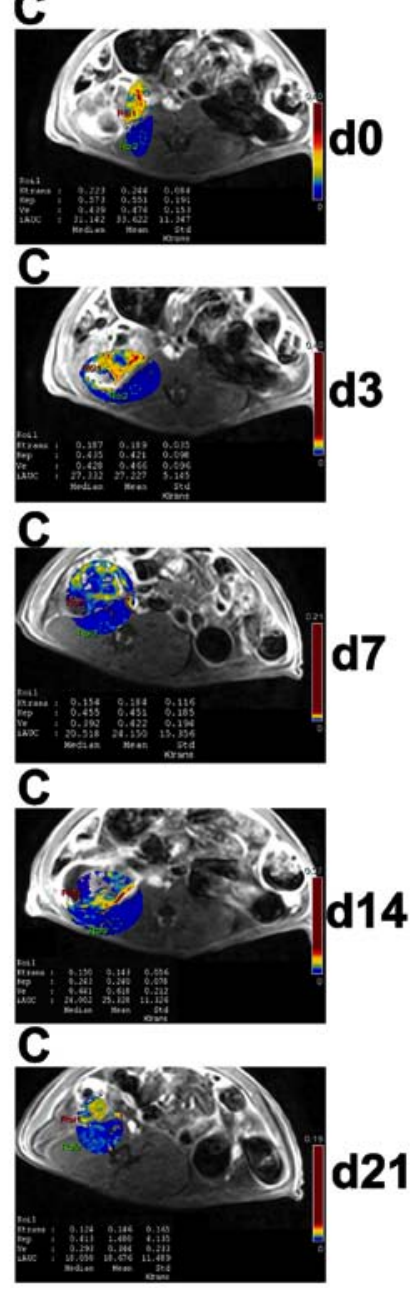

Figure 4. Conventional and DCE-MRI of EOC in sensitive rats at different time points. In the right adnexal area, a multilocular cystic-solid EOC (red arrow) progressively became smaller on T2WI (A). On DCE-MRI, ROI 1 and ROI 2 were located in ovarian EOC and muscle, respectively (B); DCE-MRI parameters ( $\mathrm{K}^{\text {trans }}, \mathrm{k}_{\mathrm{ep}}, \mathrm{v}_{\mathrm{e}}$ and IAUC) of EOC in ROI 1 were obtained by quantitatively analyzing software on pseudo-color images (C). DCE-MRI, dynamic contrast enhanced magnetic resonance imaging; EOC, epithelial ovarian cancer; T2WI, T2-weighted imaging; ROI, region of interest; $\mathrm{K}^{\text {trans }}$, volume transfer constant; $\mathrm{k}_{\mathrm{ep}}$, rate constant; $\mathrm{v}_{\mathrm{e}}$, extravascular extracellular space volume ratio; IAUC, initial area under the curve. 

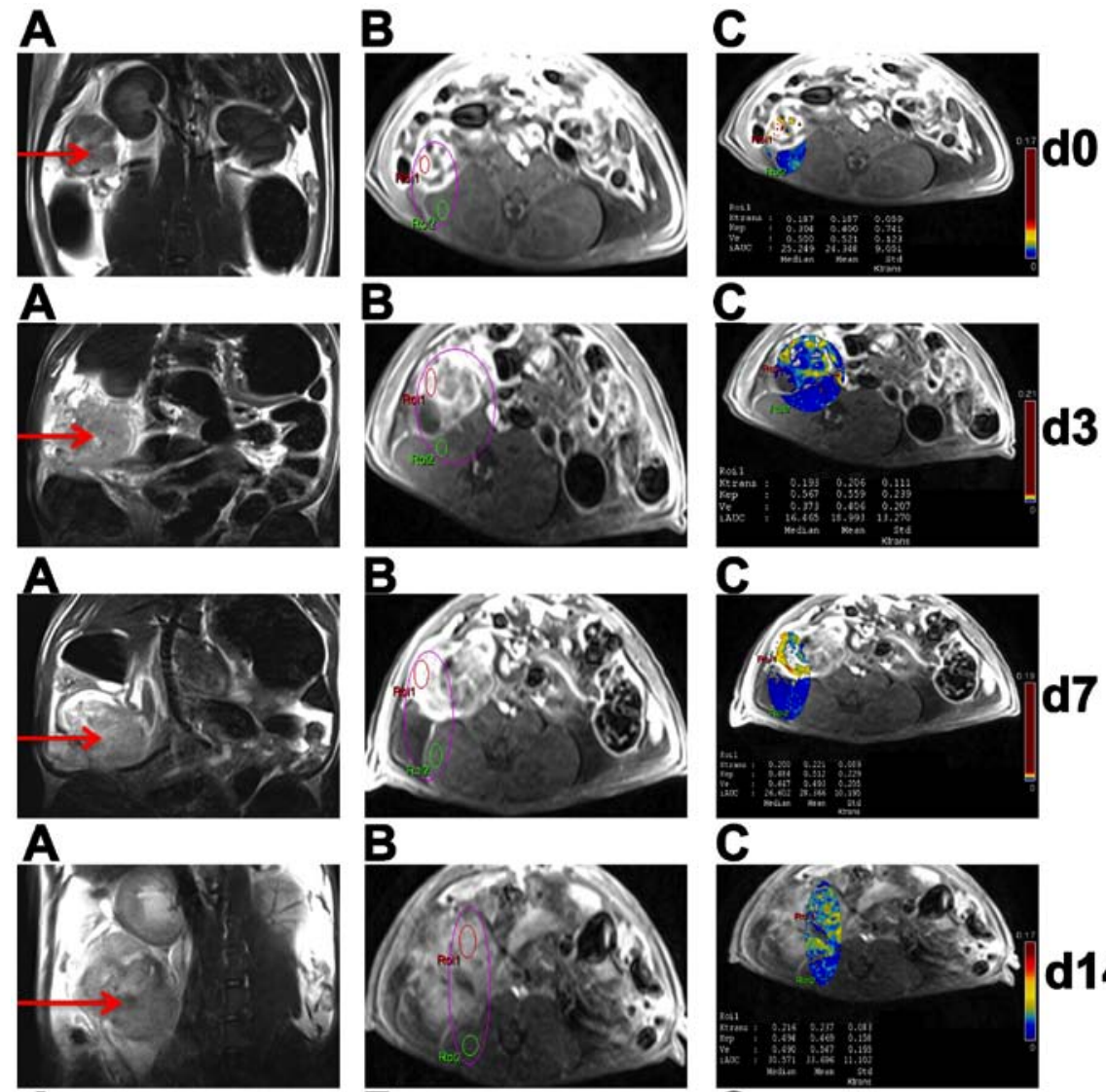

B
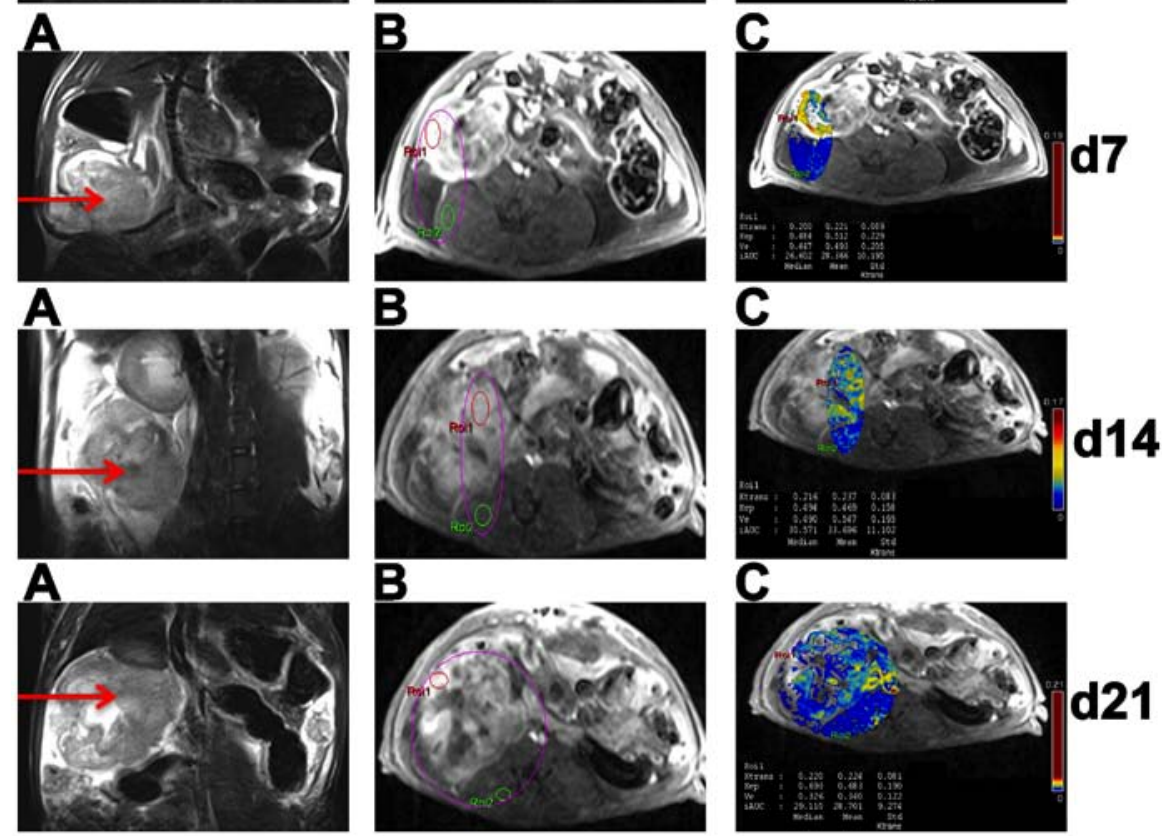

Figure 5. Conventional and DCE-MRI of EOCs in insensitive rat at different time points. In the right adnexal area, a multilocular cystic-solid EOC (red arrow) progressively became larger on T2WI (A). On DCE-MRI, ROI 1 and ROI 2 were located in ovarian EOC and muscle, respectively (B); DCE-MRI parameters $\left(\mathrm{K}^{\text {trans }}, \mathrm{k}_{\mathrm{ep}}, \mathrm{v}_{\mathrm{e}}\right.$ and IAUC) of EOC in ROI 1 were obtained by quantitatively analyzing software on pseudo-color images (C). DCE-MRI, dynamic contrast enhanced magnetic resonance imaging; EOC, epithelial ovarian cancer; T2WI, T2-weighted imaging; ROI, region of interest; $\mathrm{K}^{\text {trans }}$, volume transfer constant; $\mathrm{k}_{\mathrm{ep}}$, rate constant; $\mathrm{v}_{\mathrm{e}}$, extravascular extracellular space volume ratio; IAUC, initial area under the curve.

insensitive or control groups, for monitoring and evaluating the response to DTX therapy in EOC. On day $14, \mathrm{~K}^{\text {trans }}$ and $\mathrm{k}_{\mathrm{ep}}$ were able to be used to evaluate the efficacy of DTX in EOC, and the AUCs, sensitivities and specificities of $\mathrm{K}^{\text {trans }}$ and $\mathrm{k}_{\mathrm{ep}}$ were 0.917 and $0.889,83.3$ and $100 \%$ and 100 and $66.7 \%$, respectively. On day 21 , the AUCs, sensitivities and specificities of the two parameters were 0.917 and $0.917,83.3$ and $100 \%$ and 83.3 and $83.3 \%$, respectively. However, as early as day 3 , the percentage changes in $\mathrm{K}^{\text {trans }}$ combined with $\mathrm{k}_{\mathrm{ep}}$ were able to be used to evaluate the efficacy of DTX in EOC, and the AUC, sensitivity and specificity were 1,100 and $100 \%$, respectively. Youden's index revealed a $17.59 \%$ reduction in $\mathrm{K}^{\text {trans }}$ and $\mathrm{k}_{\mathrm{ep}}$.

Effective DTX therapy decreases MVD and VEGF expression in rat EOC. On day 3, the treatment group was divided into the sensitive and insensitive groups, with a $\sim 17.59 \%$ reduction in $\mathrm{K}^{\text {trans }}$ and $\mathrm{k}_{\mathrm{ep}}$. The specimens collected from the rats with EOC are described in Table I. As presented in Figs. 6 and 7 and Table IV, on days 7, 14 and 21, the MVD and VEGF expression levels or the percentage change in the MVD and VEGF expression levels were significantly different between the three groups and pairwise comparisons $(\mathrm{P}<0.05)$, except for in the insensitive group compared with the control group $(\mathrm{P}>0.05)$.

Tumor necrosis in rat EOC following DTX therapy. As presented in Fig. 8 and Table V, the tumor necrosis or the percentage change in necrosis rates lacked significant differences among the three groups on days 3 and $7(\mathrm{P}>0.05)$. Significant differences were observed between the sensitive and insensitive or control groups $(\mathrm{P}<0.05)$, but not between the insensitive and control groups $(\mathrm{P}>0.05)$ on days 14 and 21 .

Correlations between the percentage change in DCE-MRI parameters and the percentage change in tumor size, $M V D$, $V E G F$ expression levels and tumor necrosis. As presented in Table VI, the percentage change in $\mathrm{K}^{\text {trans }}$ had a moderately positive correlation with the percentage change in tumor size, MVD and VEGF expression levels $(\mathrm{P}<0.01)$ and a moderately 
Table IV. Changes in MVD and VEGF expression levels at different time points (\%).

\begin{tabular}{|c|c|c|c|}
\hline Day & Group & $\%$ Change in the MVD & $\%$ Change in VEGF levels \\
\hline \multirow[t]{3}{*}{ Day 3} & Sensitive group & $-7.70 \pm 6.73$ & $-16.62 \pm 15.82$ \\
\hline & Insensitive group & $-0.32 \pm 2.54$ & $-2.03 \pm 9.97$ \\
\hline & Control group & $4.09 \pm 9.21$ & $5.99 \pm 30.07$ \\
\hline \multirow[t]{3}{*}{ Day 7} & Sensitive group & $-25.82 \pm 4.03^{\mathrm{a}, \mathrm{b}}$ & $-36.59 \pm 11.00^{\mathrm{a}, \mathrm{b}}$ \\
\hline & Insensitive group & $-1.03 \pm 7.66$ & $-3.08 \pm 2.42$ \\
\hline & Control group & $9.27 \pm 9.89$ & $13.76 \pm 13.79$ \\
\hline \multirow[t]{3}{*}{ Day 14} & Sensitive group & $-26.34 \pm 4.10^{\mathrm{a}, \mathrm{b}}$ & $-39.84 \pm 7.50^{\mathrm{a}, \mathrm{b}}$ \\
\hline & Insensitive group & $-4.64 \pm 2.66$ & $-1.76 \pm 8.33$ \\
\hline & Control group & $12.87 \pm 9.41$ & $17.71 \pm 17.87$ \\
\hline \multirow[t]{3}{*}{ Day 21} & Sensitive group & $-30.84 \pm 5.05^{\mathrm{a}, \mathrm{b}}$ & $-40.20 \pm 9.88^{\mathrm{a}, \mathrm{b}}$ \\
\hline & Insensitive group & $-1.27 \pm 3.35$ & $-3.13 \pm 5.18$ \\
\hline & Control group & $17.02 \pm 8.64$ & $17.93 \pm 15.32$ \\
\hline
\end{tabular}

${ }^{\mathrm{a}} \mathrm{P}<0.05$ vs. control; ${ }^{\mathrm{b}} \mathrm{P}<0.05$ vs. insensitive. MVD, microvessel density; VEGF, vascular endothelial growth factor.

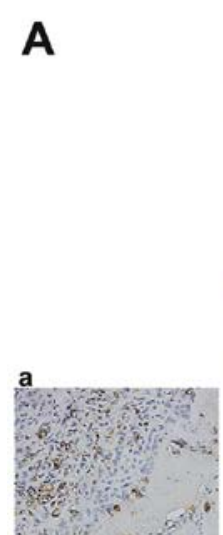

B

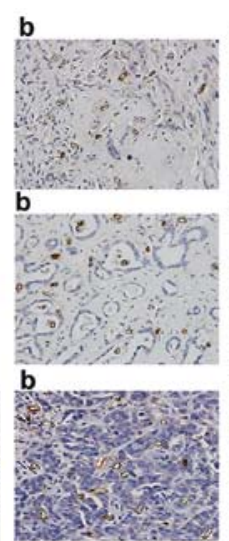

Day3
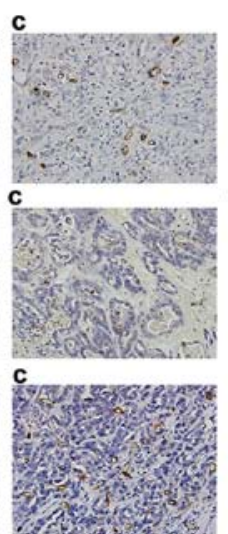

Day7 d

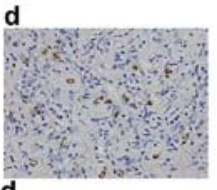

d

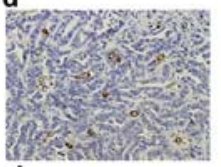

d

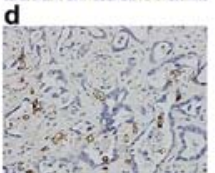

Day14

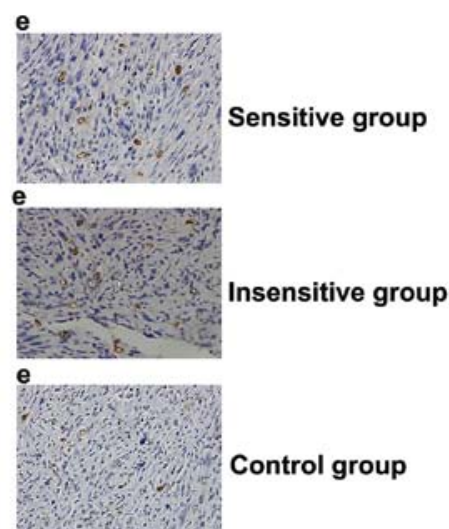

Day21

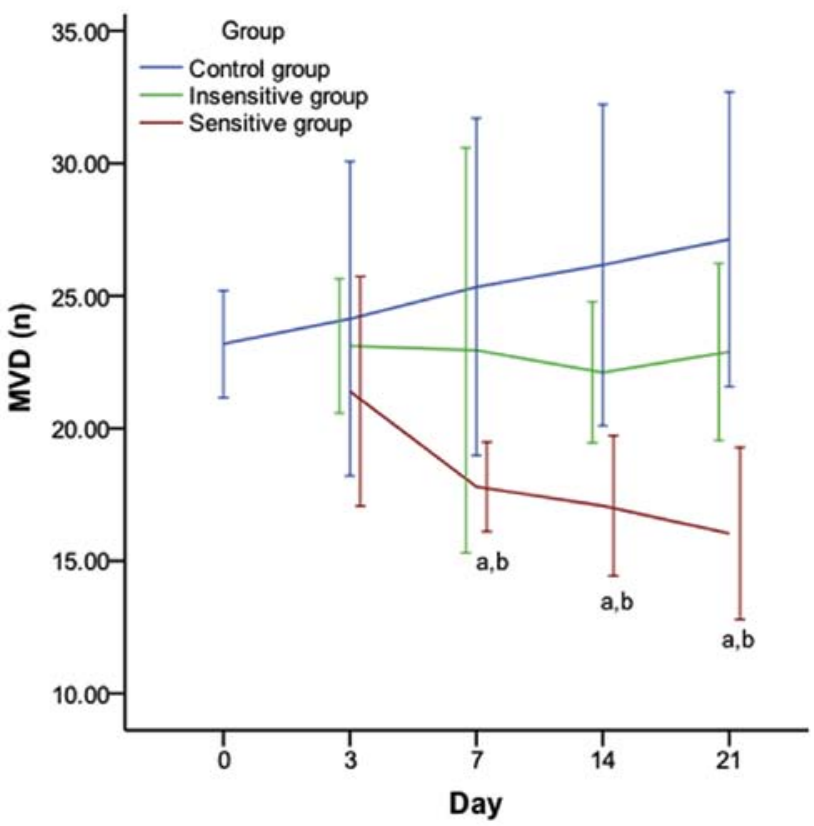

Figure 6. Effect of DTX on MVD in rat EOC. Images obtained under a microscope (high power field magnification, x200) on (a) day 0, (b) day 3, (c) day 7, (d) day 14, (e) day 21 post-treatment, presenting the expression of MVD (A), which were observed to have brown microvessels. The MVD decreased in the sensitive group, but increased in the insensitive or control group. On days 7, 14 and 21, MVD expression (B) was significantly different between the three groups and pairwise comparisons, except for insensitive vs. control. Data are represented as means \pm standard deviation. ${ }^{\mathrm{a}} \mathrm{P}<0.05$ vs. control; ${ }^{\mathrm{b}} \mathrm{P}<0.05 \mathrm{vs}$. insensitive. DTX, docataxel; MVD, microvessel density; EOC, epithelial ovarian cancer. 
Table V. Change in tumor necrosis at different time points (\%).

\begin{tabular}{lcccc}
\hline Group & Day 3 & Day 7 & Day 14 & Day 21 \\
\hline Sensitive & $75.98 \pm 36.30$ & $90.21 \pm 24.05$ & $177.58 \pm 45.00^{\mathrm{a}, \mathrm{b}}$ & $274.26 \pm 20.62^{\mathrm{a}, \mathrm{b}}$ \\
Insensitive & $12.95 \pm 21.83$ & $27.81 \pm 15.42$ & $43.67 \pm 10.47$ & $47.78 \pm 20.09$ \\
Control & $16.46 \pm 24.71$ & $22.60 \pm 16.04$ & $29.81 \pm 16.18$ & $40.80 \pm 19.99$ \\
\hline
\end{tabular}

${ }^{\mathrm{a}} \mathrm{P}<0.05$ vs. control; ${ }^{\mathrm{b}} \mathrm{P}<0.05$ vs. insensitive.

A

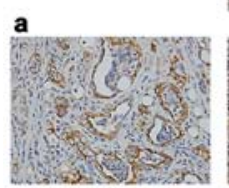

B Day 0
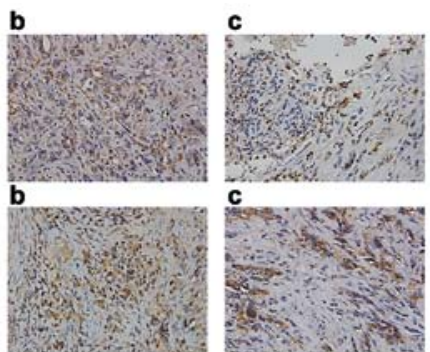

b

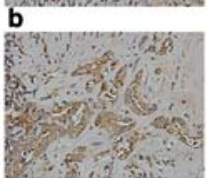

Day 3
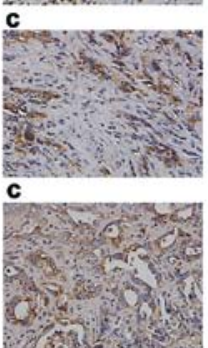

Day 7

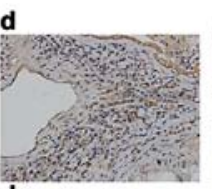

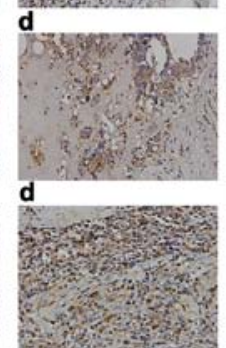

Day 14

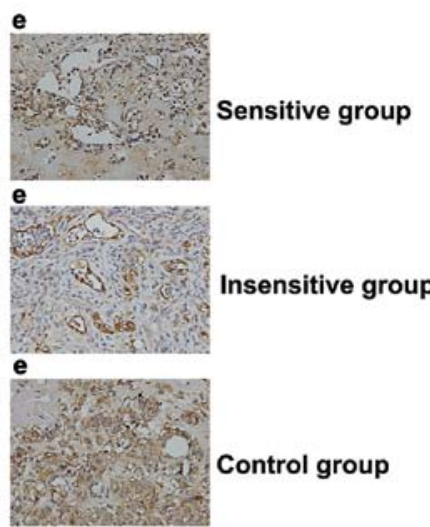

Day 21

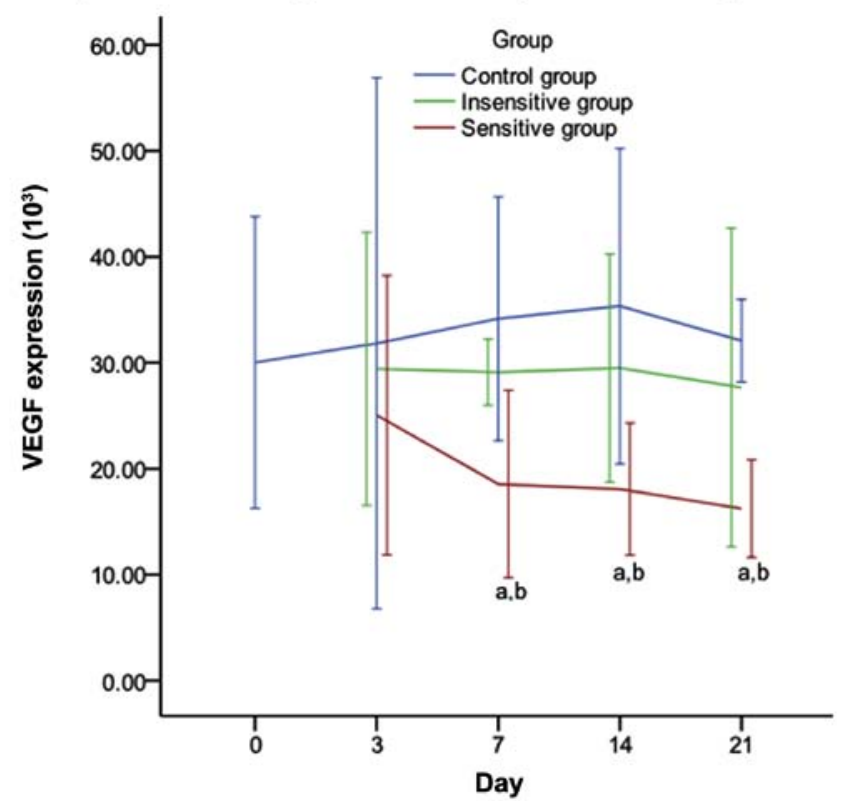

Figure 7. Effect of DTX on VEGF expression in rat EOC. Images obtained under a microscope (high power field magnification, x200) on (a) day 0, (b) day 3 , (c) day 7, (d) day 14, (e) day 21 post-treatment, presenting the immunohistochemical expression of VEGF (A), which was observed to have brownish yellow granules in the cytoplasm and intercellular spaces. The expression of VEGF (B) decreased in the sensitive group, but increased in the insensitive or control group. On days 7, 14 and 21, VEGF expression was significantly different between the three groups and pairwise comparisons, except for insensitive vs. control. Data are represented as means \pm standard deviation. ${ }^{a} \mathrm{P}<0.05$ vs. control; ${ }^{\text {b }} \mathrm{P}<0.05$ vs. insensitive. DTX, docataxel; VEGF, vascular endothelial growth factor; EOC, epithelial ovarian cancer.

negative correlation with the percentage change in tumor necrosis rates. The percentage change in $\mathrm{k}_{\mathrm{ep}}$ was moderately positively correlated with the percentage change in tumor size and MVD; there was a weak positive correlation with the percentage change VEGF expression levels and a moderate negative correlation with the percentage change in tumor necrosis rates $(\mathrm{P}<0.01)$. No significant correlation was observed between the percentage change in $\mathrm{v}_{\mathrm{e}}$ and tumor size, MVD, VEGF expression levels or tumor necrosis rates $(\mathrm{P}>0.05)$. The IAUC was weakly positively correlated with the percentage change in tumor size, moderately positively correlated with the percentage change in MVD and VEGF expression levels and weakly negatively correlated with the percentage change in tumor necrosis rates $(\mathrm{P}<0.01)$. 
Table VI. Correlation between the percentage change in dynamic contrast enhanced-magnetic resonance imaging parameters and the percentage change in tumor size, VEGF levels, MVD and necrosis.

\begin{tabular}{|c|c|c|c|c|c|c|c|c|}
\hline \multirow[b]{2}{*}{ Tumor characteristics } & \multicolumn{2}{|c|}{$\begin{array}{l}\% \text { Change in volume } \\
\text { transfer constant }\end{array}$} & \multicolumn{2}{|c|}{$\begin{array}{l}\% \text { Change in } \\
\text { rate constant }\end{array}$} & \multicolumn{2}{|c|}{$\begin{array}{c}\text { \% Change in extravascular } \\
\text { extracellular space } \\
\text { volume ratio }\end{array}$} & \multicolumn{2}{|c|}{$\begin{array}{l}\% \text { Change in initial } \\
\text { area under the curve }\end{array}$} \\
\hline & r-value & P-value & r-value & P-value & r-value & P-value & r-value & P-value \\
\hline$\%$ Change in diameter & 0.735 & $<0.001$ & 0.589 & $<0.001$ & -0.060 & 0.499 & 0.410 & $<0.001$ \\
\hline \% Change in MVD & 0.748 & $<0.001$ & 0.450 & 0.001 & 0.126 & 0.375 & 0.638 & $<0.001$ \\
\hline$\%$ Change in VEGF levels & 0.728 & $<0.001$ & 0.386 & 0.005 & 0.239 & 0.084 & 0.639 & $<0.001$ \\
\hline$\%$ Change in necrosis & -0.554 & $<0.001$ & -0.524 & $<0.001$ & -0.115 & 0.417 & -0.411 & 0.001 \\
\hline
\end{tabular}

MVD, microvessel density; VEGF, vascular endothelial growth factor.

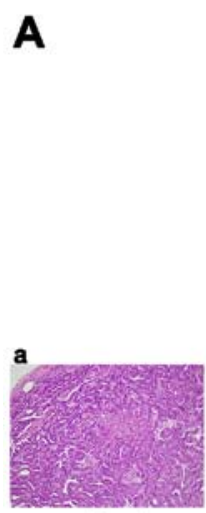

Day 0

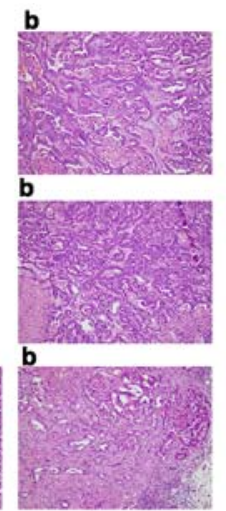

Day 3
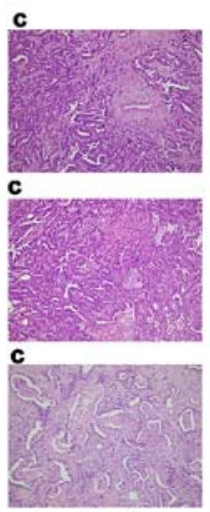

Day 7
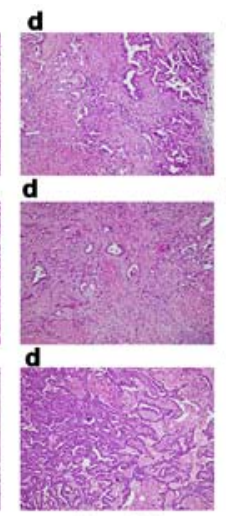

Day 14

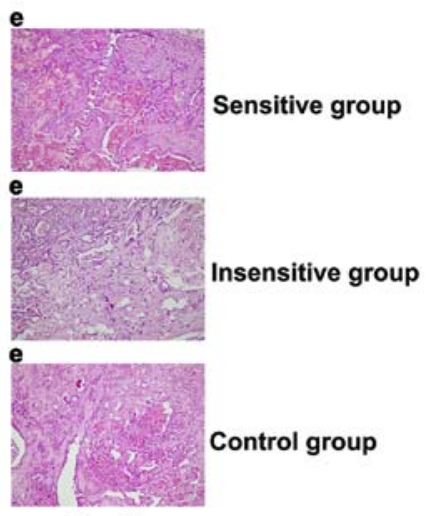

Day 21

\section{B}

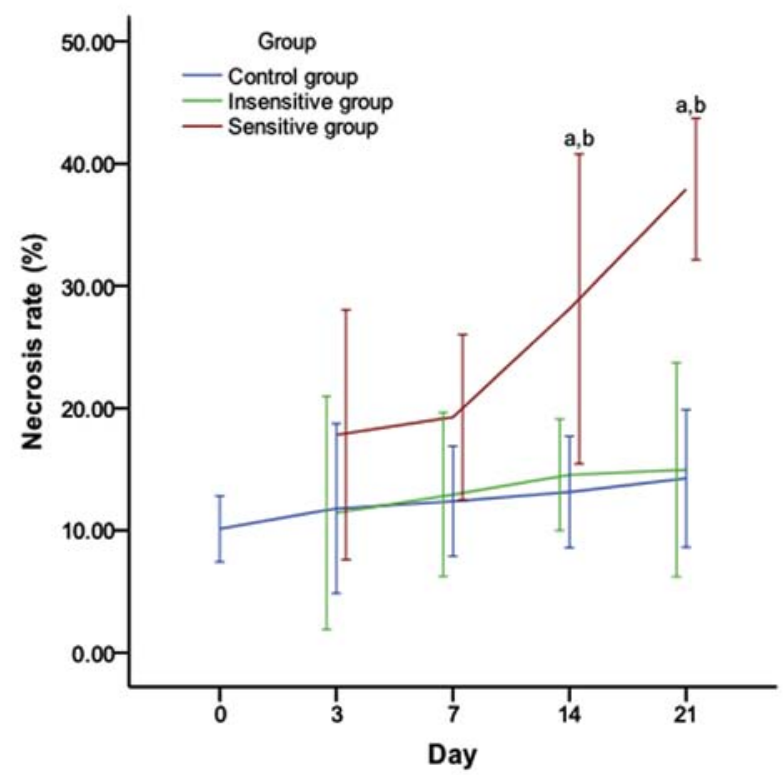

Figure 8. Effect of DTX on tumor necrosis in rat EOC. Images obtained under a microscope (high power field magnification, x200) on (a) day 0, (b) day 3 , (c) day 7, (d) day 14 and (e) day 21 post-treatment, presenting the histopathology of (A) EOC specimens, which were observed to have spotty or patchy necrosis scattering. Tumor necrosis increased in the sensitive group over time, but demonstrated no notable change in the insensitive or control group. (B) On days 14 and 21 , tumor necrosis rates were significantly different between the three groups, except for the insensitive group vs. the control group. Data are represented as means \pm standard deviation. ${ }^{\mathrm{a}} \mathrm{P}<0.05$ vs. control; ${ }^{\mathrm{b}} \mathrm{P}<0.05$ vs. insensitive. DTX, docataxel; EOC, epithelial ovarian cancer.

\section{Discussion}

DTX is a chemotherapy drug that is commonly used to treat EOC, and one of its notable antitumor mechanisms is associated with its inhibitory effect on angiogenesis $(3,23)$. Previous studies on breast, cervical, spine and other cancer types have revealed that quantitative DCE-MRI parameters may be able to detect a treatment response prior to a change 
in the tumor size (11-15,24). Cebulla et al (15) demonstrated that DCE-MRI may detect cellular and vascular responses to phosphoinositide 3-kinase/mammalian target of rapamycin inhibition in vivo in ovarian cancer xenografts. In the present study, quantitative DCE-MRI was applied to analyze the early treatment response to DTX in induced rat EOC.

The present study demonstrated that there were significantly higher percentage changes in $\mathrm{K}^{\text {trans }}, \mathrm{k}_{\mathrm{ep}}$ and IAUC in the DTX sensitive group compared with its insensitive and control counterparts between day 3 and day 21. However, differences in these parameters themselves were not observed until day 14 or 21 . Early during the treatment process (on day 3), the percentage change of $\mathrm{K}^{\text {trans }}$ combined with $\mathrm{k}_{\mathrm{ep}}$ had an AUC of 1 and a sensitivity and specificity of 100 and $100 \%$, respectively (which may be used for detecting the response to DTX), using a cut-off value of a $17.59 \%$ reduction in $\mathrm{K}^{\text {trans }}$ and $\mathrm{k}_{\mathrm{ep}}$. These results illustrated that the percentage change in the DCE-MRI parameters were more effective compared with the DCE-MRI parameters alone in detecting the tumor response to chemotherapeutic agents in individual animals. Therefore, they may be reliable biomarkers for monitoring the tumor response to chemotherapy and for determining individualized therapeutic methods.

For oncologists, a change in tumor size according to guidelines such as RECIST is the most commonly used method of assessing the tumor response to chemotherapy (25). In the present study, the percentage change in the tumor size observed using MRI was significantly higher in the DTX sensitive group compared with its insensitive counterpart from day 7 onwards, and its control counterpart from day 14 onwards. However, neither the tumor size nor its percentage change achieved a perfect result of an AUC of 1, a sensitivity of $100 \%$ and a specificity of $100 \%$ for the monitoring of the response of EOC to DTX until day 21. These results suggested that the percentage changes in $\mathrm{K}^{\text {trans }}, \mathrm{k}_{\mathrm{ep}}$ and IAUC reflected more effectively and more quickly the efficacy of DTX treatment compared with the percentage change in the size of the tumor. And more importantly, quantitative DCE-MRI parameters $\left(\mathrm{K}^{\text {trans }}, \mathrm{k}_{\mathrm{ep}}\right.$ and IAUC) were superior to imaging tumor size for early detection of response to DTX chemotherapy in EOCs.

$\mathrm{K}^{\text {trans }}$ and $\mathrm{k}_{\mathrm{ep}}$ reflect the tissue perfusion, vascular permeability and tumor angiogenesis (26-28). $\mathrm{V}_{\mathrm{e}}$ indirectly represents the appearance of tumor angiogenesis (29). IAUC is associated with the blood flow, volume and interstitial space of the tumor, and it is the comprehensive reflection of the changes in $\mathrm{K}^{\text {trans }}, \mathrm{k}_{\mathrm{ep}}$ and $\mathrm{v}_{\mathrm{e}}(30)$. DCE-MRI is being increasingly used in research to detect the treatment response to targeted antiangiogenic agents by demonstrating the occurrence of vascular disruption and changes in the microcirculation (31). A study by Li et al (32) demonstrated that the DCE-MRI parameters Krans and $\mathrm{k}_{\mathrm{ep}}$ allowed for the estimation of angiogenesis in breast cancer and predicted breast cancer prognosis. Tumor growth or development is accompanied by angiogenesis. Consequently, tumor growth results in higher $\mathrm{K}^{\text {trans }}, \mathrm{k}_{\mathrm{ep}}$ and IAUC values (33). By contrast, effective DTX treatment blocks neovascularization, which in turn decreases the $\mathrm{K}^{\text {trans }}, \mathrm{k}_{\mathrm{ep}}$ and IAUC values.

As early as the 1970s, Folkman (34) demonstrated that angiogenesis was essential for the survival and sustained growth of solid tumor types and proposed the theory of anti-angiogenic therapy for a tumor. MVD has been accepted as a standard indicator of angiogenesis that is tightly regulated by pro-angiogenic and anti-endothelial growth factors (35). VEGF is one of the most necessary pro-angiogenic growth factors, and it has appeared to be essential in the angiogenic process $(36,37)$. Our previous study demonstrated that $\mathrm{K}^{\text {trans }}$, $\mathrm{k}_{\mathrm{ep}}$ and IAUC were positively correlated with MVD and VEGF expression, which suggested that changes of $\mathrm{K}^{\text {trans }}, \mathrm{k}_{\mathrm{ep}}$ and IAUC induced by antiangiogenic therapy may reflect changes of MVD and VEGF (17).

When the treatment group of the present study was divided into sensitive and insensitive groups according to a cut-off value of a $17.59 \%$ reduction in $\mathrm{K}^{\text {trans }}$ and $\mathrm{k}_{\mathrm{ep}}$ values on day 3 , comprehensive histopathology analysis at each time point demonstrated that the MVD and VEGF expression levels in EOC were notably decreased in the sensitive group compared with the insensitive group in addition to the control group on day 7 . The results of the present study were in accordance with the results of Ji et al (38) and Zhang et al $(39,40)$. The present results indicated that DTX chemotherapy had inhibitory effects on angiogenesis by decreasing the MVD count and VEGF expression levels, and treatment-induced hemodynamics changes occurred prior to changes in the tumor morphology.

Chen et al (41) demonstrated that $\mathrm{K}^{\text {trans }}$ and IAUC were moderately positively correlated with MVD, while the $\mathrm{k}_{\mathrm{ep}}$ and $\mathrm{v}_{\mathrm{e}}$ values were not correlated with MVD subsequent to percutaneous ethanol injection in a rabbit VX2 liver tumor. According to a study by Yuan et al (42), the $\mathrm{K}^{\text {trans }}$ value, which reflects the perfusion and permeability of tumor microvessels, was highest in VEGF189-overexpressing tumor types. The results of the present study additionally revealed that changes in the $\mathrm{K}^{\text {trans }}$, $\mathrm{k}_{\mathrm{ep}}$ and IAUC values were positively correlated with changes in MVD and VEGF. Additionally, dynamic changes in these parameters may noninvasively reflect the expression of tumor biomarkers in vivo.

Histopathological analysis demonstrated more prominent necrosis in the sensitive group compared with the insensitive and control counterparts from day 14 onwards, which was concurrent with, but occurred later compared with, the results of the analysis of the quantitative DCE-MRI parameters. Furthermore, the percentage changes in the $\mathrm{K}^{\text {trans }}, \mathrm{k}_{\mathrm{ep}}$ and IAUC values were positively correlated with that of the necrosis rates. These results demonstrated that the changes in DCE-MRI parameters may help to predict the tumor histopathological responses and monitor the effectiveness of DTX treatment.

However, the present study also had limitations. For example, 3.0 T MRI was used. In order to improve the image resolution, 7.0 T MRI will be applied in future studies. Neither DCE-MRI nor angiogenesis were analyzed regionally, and the vascular variant in the tumor and normal tissue junction was the greatest. Furthermore, the vascular variant may have affected the overall stability of tumor angiogenesis (43).

In conclusion, the results of the present study indicated that the quantitative DCE-MRI parameters were superior to imaging tumor size for the detection of tumor histopathological responses for the early detection of responses to DTX in EOC. Quantitative DCE-MRI parameters may contribute to adjusting the treatment regimen for non-responders sooner in the progression of the disease and improving the prognosis. 


\section{Acknowledgements}

Not applicable.

\section{Funding}

The present study was supported by the Shanghai Municipal Health Bureau Commission of Health and Family Planning (grant no 20134y156).

\section{Availability of data and materials}

All data generated or analyzed during this study are included in this published article.

\section{Authors' contributions}

JWQ conceived the study concepts and study design, and defined the intellectual content. SJY and SQC performed the data analysis, acquired the data and performed the literature research. SJY edited the manuscript. TKQ was involved in the conception of the study. All authors read and approved the final manuscript and agree to be accountable for all aspects of the research in ensuring that the accuracy or integrity of any part of the work are appropriately investigated and resolved.

\section{Ethics approval and consent to participate}

All animal experimental procedures were ethically approved by the Institutional Review Board of Jinshan Hospital of Fudan University (Shanghai, China) and were performed according to the Guide for the Care and Use of Laboratory Animals of the National Science and Technology Committee of China.

\section{Patient consent for publication}

Not applicable.

\section{Competing interests}

The authors declare that they have no competing interests.

\section{References}

1. Pan $\mathrm{Z}$ and Xie X: BRCA mutations in the manifestation and treatment of ovarian cancer. Oncotarget 8: 97657-97670, 2017.

2. Köbel M, Kalloger SE, Boyd N, McKinney S, Mehl E, Palmer C, Leung S, Bowen NJ, Ionescu DN, Rajput A, et al: Ovarian carcinoma subtypes are different diseases: Implications for biomarker studies. PLoS Med 5: e232, 2008.

3. Chen ZK, Cai MX, Yang J, Lin LW, Xue ES, Huang J, Wei HF, Zhang XJ and Ke LM: Chemotherapy with PLGA microspheres containing docetaxel decreases angiogenesis in human hepatoma xenograft. Med Oncol 29: 62-69, 2012.

4. Razi Soofiyani S, Mohammad Hoseini A, Mohammadi A, Khaze Shahgoli V, Baradaran B and Hejazi MS: siRNA-mediated silencing of CIP2A enhances docetaxel activity against PC-3 prostate cancer cells. Adv Pharm Bull 7: 637-643, 2017.

5. Liu P, Feng J, Sun M, Yuan W, Xiao R, Xiong J, Huang X, Xiong M, Chen W, Yu X, et al: Synergistic effects of baicalein with gemcitabine or docetaxel on the proliferation, migration and apoptosis of pancreatic cancer cells. Int J Oncol 51: 1878-1886, 2017.
6. Du Z, Li L, Sun W, Wang X, Zhang Y, Chen Z, Yuan M, Quan Z, Liu N, Hao Y, et al: HepaCAM inhibits the malignant behavior of castration-resistant prostate cancer cells by downregulating Notch signaling and PF-3084014 (a $\gamma$-secretase inhibitor) partly reverses the resistance of refractory prostate cancer to docetaxel and enzalutamide in vitro. Int J Oncol 53: 99-112, 2018.

7. Armstrong SR, Narendrula R, Guo B, Parissenti AM, McCallum KL, Cull S and Lannér C: Distinct genetic alterations occur in ovarian tumor cells selected for combined resistance to carboplatin and docetaxel. J Ovarian Res 5: 40, 2012.

8. Cohen JG, White M, Cruz A and Farias-Eisner R: In 2014, can we do better than CA125 in the early detection of ovarian cancer? World J Biol Chem 5: 286-300, 2014.

9. Therasse P, Arbuck SG, Eisenhauer EA, Wanders J, Kaplan RS, Rubinstein L, Verweij J, Van Glabbeke M, van Oosterom AT, Christian MC, et al: New guidelines to evaluate the response to treatment in solid tumors. European Organization for Research and Treatment of Cancer, National Cancer Institute of the United States, National Cancer Institute of Canada. J Natl Cancer Inst 92: 205-216, 2000.

10. Leach MO, Morgan B, Tofts PS, Buckley DL, Huang W, Horsfield MA, Chenevert TL, Collins DJ, Jackson A, Lomas D, et al: Imaging vascular function for early stage clinical trials using dynamic contrast-enhanced magnetic resonance imaging. Eur Radiol 22: 1451-1464, 2012.

11. Padhani AR and Miles KA: Multiparametric imaging of tumor response to therapy. Radiology 25: 348-364, 2010.

12. Yuh WT, Mayr NA, Jarjoura D, Wu D, Grecula JC, Lo SS, Edwards SM, Magnotta VA, Sammet S, Zhang H, et al: Predicting control of primary tumor and survival by DCE MRI during early therapy in cervical cancer. Invest Radiol 44: 343-350, 2009.

13. Jensen LR, Huuse EM, Bathen TF, Goa PE, Bofin AM, Pedersen TB, Lundgren S and Gribbestad IS: Assessment of early docetaxel response in an experimental model of human breast cancer using DCE-MRI, ex vivo HR MAS, and in vivo $1 \mathrm{H}$ MRS. NMR Biomed 23: 56-65, 2010.

14. Tudorica A, Oh KY, Chui SY, Roy N, Troxell ML, Naik A, Kemmer KA, Chen Y, Holtorf ML, Afzal A, et al: Early prediction and evaluation of breast cancer response to neoadjuvant chemotherapy using quantitative DCE-MRI. Transl Oncol 9: 8-17, 2016.

15. Cebulla J, Huuse EM, Pettersen K, van der Veen A, Kim E, Andersen S, Prestvik WS, Bofin AM, Pathak AP, Bjørkøy G, et al: MRI reveals the in vivo cellular and vascular response to BEZ235 in ovarian cancer xenografts with different PI3-kinase pathway activity. Br J Cancer 112: 504-513, 2015.

16. Lis E, Saha A, Peck KK, Zatcky J, Zelefsky MJ, Yamada Y, Holodny AI, Bilsky $\mathrm{MH}$ and Karimi S: Dynamic contrast-enhanced magnetic resonance imaging of osseous spine metastasis before and 1 hour after high-dose image-guided radiation therapy. Neurosurg Focus 42: E9, 2017.

17. Yuan SJ, Qiao TK, Qiang JW, Cai SQ and Li RK: The value of DCE-MRI in assessing histopathological and molecular biological features in induced rat epithelial ovarian carcinomas. J Ovarian Res 10: 65, 2017.

18. Tofts PS, Brix G, Buckley DL, Evelhoch JL, Henderson E, Knopp MV, Larsson HB, Lee TY, Mayr NA, Parker GJ, et al: Estimating kinetic parameters from dynamic contrast-enhanced T(1)-weighted MRI of a diffusable tracer: Standardized quantities and symbols. J Magn Reson Imaging 10: 223-232, 1999.

19. Zhang P, Chen L, Zhang Z, Lin L and Li Y: Pharmacokinetics in rats and efficacy in murine ovarian cancer model for solid lipid nanoparticles loading docetaxel. J Nanosci Nanotechnol 10: 7541-7544, 2010

20. Rustin GJ, Quinn M, Thigpen T, du Bois A, Pujade-Lauraine E, Jakobsen A, Eisenhauer E, Sagae S, Greven K, Vergote I, et al: Re: New guidelines to evaluate the response to treatment in solid tumors (ovarian cancer). J Natl Cancer Inst 96: 487-488, 2004.

21. Zhou LN, Wu N, Liang Y, Gao K, Li XY and Zhang LF: Monitoring response to gefitinib in nude mouse tumor xenografts by ${ }^{18} \mathrm{~F}$-FDG microPET-CT: Correlation between ${ }^{18} \mathrm{~F}$-FDG uptake and pathological response. World J Surg Oncol 13: 111, 2015.

22. Kovač JD, Terzić M, Mirković M, Banko B, Đikić-Rom A and Maksimović R: Endometrioid adenocarcinoma of the ovary: MRI findings with emphasis on diffusion-weighted imaging for the differentiation of ovarian tumors. Acta Radiol 57: 758-766, 2016.

23. Khatun Z, Nurunnabi, Cho KJ, Byun Y, Bae YH and Lee YK: Oral absorption mechanism and anti-angiogenesis effect of taurocholic acid-linked heparin-docetaxel conjugates. J Control Release 177: 64-73, 2014. 
24. Whisenant JG, Sorace AG, McIntyre JO, Kang H, Sánchez V, Loveless ME and Yankeelov TE: Evaluating treatment responseusing DW-MRI and DCE-MRI in trastuzumab responsive and resistant HER2-overexpressing human breast cancer xenografts. Transl Oncol 7: 768-779, 2014.

25. Eisenhauer EA, Therasse P, Bogaerts J, Schwartz LH, Sargent D, Ford R, Dancey J, Arbuck S, Gwyther S, Mooney M, et al: New response evaluation criteria in solid tumours: Revised RECIST guideline (version 1.1). Eur J Cancer 45: 228-247, 2009.

26. de Bazelaire C, Siauve N, Fournier L, Frouin F, Robert P, Clement O, de Kerviler E and Cuenod CA: Comprehensive model for simultaneous MRI determination of perfusion and permeability using a blood-pool agent in rats rhabdomyosarcoma. Eur Radiol 15: 2497-2505, 2005.

27. Boult JKR, Box G, Vinci M, Perryman L, Eccles SA, Jones C and Robinson SP: Evaluation of the response of intracranial xenografts to VEGF signaling inhibition using multiparametric MRI. Neoplasia 19: 684-694, 2017.

28. Merz M, Moehler TM, Ritsch J, Bäuerle T, Zechmann CM, Wagner B, Jauch A, Hose D, Kunz C, Hielscher T, et al: Prognostic significance of increased bone marrow microcirculation in newly diagnosed multiple myeloma: Results of a prospective DCE-MRI study. Eur Radiol 26: 1404-11, 2016.

29. Ma L, Xu X, Zhang M, Zheng S, Zhang B, Zhang W and Wang P. Dynamic contrast-enhanced MRI of gastric cancer: Correlations of the pharmacokinetic parameters with histological type, Lauren classification, and angiogenesis. Magn Reson Imaging 37: 27-32, 2017.

30. Hirashima Y, Yamada Y, Tateishi U, Kato K, Miyake M, Horita Y, Akiyoshi K, Takashima A, Okita N, Takahari D, et al: Pharmacokinetic parameters from 3-Tesla DCE-MRI as surrogate biomarkers of antitumor effects of bevacizumab plus FOLFIRI in colorectal cancer with liver metastasis. Int J Cancer 130: 2359-2365, 2012.

31. Yang J, Kim JH, Im GH, Heo H, Yoon S, Lee J, Lee JH and Jeon P: Evaluation of antiangiogenic effects of a new synthetic candidate drug KR-31831 on xenografted ovarian carcinoma using dynamic contrast enhanced MRI. Korean J Radiol 12 : 602-610, 2011.

32. Li L, Wang K, Sun X, Wang K, Sun Y, Zhang G and Shen B: Parameters of dynamic contrast-enhanced MRI as imaging markers for angiogenesis and proliferation in human breast cancer. Med Sci Monit 21: 376-382, 2015.
33. Yao WW, Zhang H, Ding B, Fu T, Jia H, Pang L, Song L, $\mathrm{Xu} \mathrm{W}$, Song Q, Chen K, et al: Rectal cancer: 3D dynamic contrast-enhanced MRI; correlation with microvascular density and clinicopathological features. Radiol Med 116: 366-374, 2011.

34. Folkman J: Tumor angiogenesis: Therapeutic implications. N Engl J Med 285: 1182-1186, 1971.

35. Mikalsen LT, Dhakal HP, Bruland OS, Nesland JM and Olsen DR: Quantification of angiogenesis in breast cancer by automated vessel identification in CD34 immunohistochemical sections. Anticancer Res 31: 4053-4060, 2011.

36. Bando $\mathrm{H}$ : Vascular endothelial growth factor and bevacitumab in breast cancer. Breast Cancer 14: 163-173, 2007.

37. Hayes DF, Miller K and Sledge G: Angiogenesis as targeted breast cancer therapy. Breast 16 (Suppl 2): S17-S19, 2007.

38. Ji Y, Hayashi K, Amoh Y, Tsuji K, Yamauchi K, Yamamoto N, Tsuchiya H, Tomita K, Bouvet M and Hoffman RM: The camptothecin derivative CPT-11 inhibits angiogenesis in a dual-color imageable orthotopic metastatic nude mouse model of human colon cancer. Anticancer Res 27: 713-718, 2007.

39. Zhang Q, Kang X and Zhao W: Antiangiogenic effect of low-dose cyclophosphamide combined with ginsenoside $\mathrm{Rg} 3$ on Lewis lung carcinoma. Biochem Biophys Res Commun 342: 824-828, 2006.

40. Zhang M, Tao W, Pan S, Sun X and Jiang H: Low-dose metronomic chemotherapy of paclitaxel synergizes with cetuximab to suppress human colon cancer xenografts. Anticancer Drugs 20: 355-363, 2009.

41. Chen J, Qian T, Zhang H, Wei C, Meng F and Yin H: Combining dynamic contrast enhanced magnetic resonance imaging and microvessel density to assess the angiogenesis after PEI in a rabbit VX2 liver tumor model. Magn Reson Imaging 34: 177-182, 2016.

42. Yuan A, Lin CY, Chou CH, Shih CM, Chen CY, Cheng HW, Chen YF, Chen JJ, Chen JH, Yang PC, et al: Functional and structural characteristics of tumor angiogenesis in lung cancers overexpressing different VEGF isoforms assessed by DCE- and SSCE-MRI. PLoS One 6: e16062, 2011.

43. Wu L, Lv P, Zhang H, Fu C, Yao X, Wang C, Zeng M, Li Y and Wang X: Dynamic contrast-enhanced (DCE) MRI assessment of microvascular characteristics in the murine orthotopic pancreatic cancer model. Magn Reson Imaging 33: 737-760, 2015. 